\title{
OS ESPAÇOS DE CULTURA COMO ARTICULADORES SOCIAIS EDUCACIONAIS E AFETIVOS
}

\author{
Fabrícia Dias da Cunha de Moraes Fernandes, Raphaela Leticia Rozendo Pinto \\ Universidade do Oeste Paulista - UNOESTE, Presidente Prudente, SP. E-mail: rozendo.raphaela@gmail.com
}

\section{RESUMO}

O presente artigo aborda o Trabalho de Conclusão de Curso da autora que analisar a relevância dos centros culturais para toda a sociedade, principalmente como catalizadores da educação e cultura, visto estes serem pontos falhos em nosso país, já que a educação pública está distante de atingir um modelo educacional que vise o desenvolvimento da criança de forma integral. Os centros de cultura abrangem uma grande variedade de aspectos culturais, de lazer e educacionais, proporcionando um excelente meio de disseminar e propagar cultura, criando a base necessária para a preparação e transformação da sociedade atual e futura, sendo sua arquitetura fundamental para atingir tais objetivos. Portanto, o presente estudo tem como missão investigar a importância dos espaços culturais para a sociedade bem como de sua relação com a arquitetura, além de trazer propostas para implementação de centro de cultura e lazer no Conjunto Habitacional João Domingos Netto, bairro localizado na cidade de Presidente Prudente, interior do Estado de São Paulo. Para tanto a metodologia baseia-se em revisão bibliográfica e documental para a formação de uma análise sobre o tema, assim como levantamentos e visitas in loco no local em questão, visto o conjunto carecer de espaços culturais e os equipamentos de lazer.

Palavras-chave: Centros Culturais. Lazer. Conjunto Habitacional João Domingos Netto. Presidente Prudente.

\section{CULTURE SPACES AS EDUCATIONAL AND AFFECTIVE SOCIAL ARTICULATORS}

\begin{abstract}
This article addresses the author's Course Conclusion Work, which analyzes the relevance of cultural centers for the whole society, mainly as catalysts for education and culture, as these are weak points in our country, since public education is far from reaching an educational model aimed at the development of the child in an integral way. Culture centers cover a wide variety of cultural, leisure and educational aspects, providing an excellent means of disseminating and propagating culture, creating the necessary basis for the preparation and transformation of society, and their architecture is fundamental to achieve these goals. Therefore, this study aims to investigate the importance of cultural spaces for society as well as their relationship with architecture, in addition to bringing proposals for the implementation of a culture and leisure center in the João Domingos Netto Housing Complex, a neighborhood located in the city of Presidente Prudente, interior of the State of São Paulo. Therefore, the methodology is based on a bibliographical and documental review for the formation of na analysis on the theme, as well as surveys and on-site visits in the place in question, since the complex lacks cultural spaces and leisure facilities.
\end{abstract}

Keywords: Cultural centers. Leisure. João Domingos Netto. Presidente Prudente.

\section{INTRODUÇÃO}

A cultura está ligada a preocupação da sociedade contemporânea em entender os caminhos que levaram as relações humanas presentes e suas expectativas futuras. Ao se tratar de cultura, deve-se ter em mente toda a 
riqueza da humanidade e as variedades de formas de existência.

A cultura expressa a complexa realidade dos diversos grupos humanos e suas próprias particularidades que os conectam e distinguem. É importante compreender a percepção que uma realidade cultural gera para os indivíduos que estão a vivenciando (SANTOS, 1996). Ter conhecimento das causas em que as culturas variam e quais as causas destas variedades são temas que acarretam muita discussão.

De acordo com Milanesi (1997), é caracterizado como centro de cultura a união de produtos culturais, a oportunidade de argumentá-los e a oportunidade de elaborar novos produtos. Por isso, pode-se compreender que um centro cultural é um local de ajuntamento de atividades culturais, onde gera criação, reflexão, fruição e compartilhamento de bens culturais.

Assim, entendendo a dinâmica e a importância da cultura e dos centros de propagação de cultura o presente estudo surge a partir da percepção que no Conjunto Habitacional João Domingos Netto, localizado na zona norte da cidade de Presidente Prudente, se dá pela falta de incentivo e de espaços físicos de lazer, cultura e educação no local, sendo um bairro totalmente marginalizado pelo restante da cidade.

O presente trabalho visa, além de discutir e debater sobre centros de cultura, propor por meio de diretrizes arquitetônicas um centro no bairro em questão, que estabeleça uma relação significativa de pertencimento com os usuários, que fomente a interação entre os moradores e uma identidade ao local, e assim, possibilitar atividades extracurriculares como aulas de dança, música, teatro e diversos outros tipos de manifestações culturais.

\section{MÉTODOS}

A metodologia do presente artigo baseou-se em revisão bibliográfica e documental em materiais publicados como artigos, livros e periódicos para a formação de uma análise sobre o tema que envolvem a análise da importância de polos de cultura para a sociedade, seu contexto histórico no Brasil e ao redor do mundo, assim como breve estudo sobre a cidade de Presidente Prudente e sua relação com espaços de cultura, com ênfase no Conjunto Habitacional João Domingos Netto. Para traçar da melhor forma as diretrizes projetuais foi necessário visitas in loco, estabelecendo assim levantamentos fotográficas e métricos, assim como compreensão da dinâmica espacial, urbana e social do local.

\section{CULTURA E CENTROS CULTURAIS}

Santos (1996) define cultura como uma preocupação da sociedade contemporânea em entender os caminhos que levaram as relações humanas presentes e suas expectativas futuras. Ter conhecimento das causas em que as culturas variam e quais as causas destas variedades são temas que acarretam muita discussão.

Ao se tratar de cultura, deve-se ter em mente toda a riqueza da humanidade e as variedades de formas de existência. A cultura expressa a complexa realidade dos diversos grupos humanos e suas próprias particularidades que os conectam e distinguem. É importante compreender a percepção que uma realidade cultural gera para os indivíduos que estão a vivenciando (SANTOS, 1996).

A cultura pode apontar para diversas atividades do ser humano não se restringindo às tradicionais (literatura, pintura, cinema - em suma, as que se apresentam sob uma forma estética) mas se abrem para uma rede de significações ou linguagens incluindo tanto a cultura popular (carnaval) como a publicidade, a moda, o comportamento (ou a atitude), a festa, o consumo, o estar-junto (COELHO, 1997).

Conforme Santos (1996), essas questões são causadas pelas relações entre os integrantes das sociedades que são definidas pelas desigualdades, sendo assim, a posse dessa produção comum se faz para beneficiar os interesses que comandam o processo social. Em consequência desse fator, a própria cultura, apresenta grandes marcas de desigualdade.

Segundo Coelho (1997), é necessário que as diferentes culturas de grupos, meios sociais, classes, e seguimentos de classes mantenham, cada uma, sua particularidade ao mesmo tempo que entrar em equilíbrio umas com as outras, sem que se tenha entre elas a relação de poder sobre a outra.

Nenhuma sociedade faz a cultura essencial porque Ihe sobram recursos, mas, ao contrário, porque há carências a serem superadas. Os países mais desenvolvidos são aqueles que investem nas atividades educacionais e na cultura, nos programas de informação, nas formas 
que a sociedade encontra para tonar o conhecimento acessível a todos os cidadãos e nos esforços que faz para ampliar o conhecimento (MILANESI, 1997, p. 269).

Com a afirmação acima, pode se compreender que o conhecimento não é apenas necessário para produzir riquezas e rete-las, mas para dividi-las. Somente a partir desse ideal será possível a construção de um país igualitário, cujas políticas públicas atendam indistintamente a todos os cidadãos (MILANESI, 1997).

Chaui (2008), fala a respeito da relação entre cultura e democracia, apresentando alguns problemas enfrentados pela cultura democrática. Ela aponta que o primeiro problema é a relação entre cultura e Estado; em segundo, a relação entre cultura e mercado; em terceiro, a relação entre cultura e criadores.

Ao examinar o modo que o estado opera no Brasil em relação ao tratamento da cultura, pode-se dizer que sua tendencia foi antidemocrática. Independente do grupo dirigente, mas pelo modo mesmo que o Estado propôs a cultura, procurando trazer toda criação social da cultura com a justificativa de ampliação do campo cultural público, transformando a criação social em cultura oficial, fazendo dela regra para que a sociedade siga (CHAUI, 2008).

Segundo Chaui (2008), para compreender por que o Estado não pode ser produtor de cultura é preciso retomar a concepção antropológica abrangente abordada anteriormente - a cultura como atividade social que institui um campo de símbolos e signos, de valores, comportamentos e práticas - porém acrescentando, que há campos diversos campos culturais dentro da sociedade, por conta da divisão social das classes e da diversidade de grupos e movimentos sociais.

Nessa visão múltipla da cultura, ainda dentro desse campo da sua definição filosóficoantropológica, o Estado passa, a ser visto, como um dos elementos que integram a cultura, isto é, como uma das maneiras pelas quais, em condições históricas determinadas e a divisão social das classes, uma sociedade cria para si, os símbolos, os signos e as imagens do poder. "O Estado é produto da cultura e não produtor de cultura. E um produto que exprime a divisão e a multiplicidade sociais" (CHAUI, 2008, p. 64).
De acordo com Chaui (2008), não que a cultura não deva ter um lado de lazer que é essencial, mas uma coisa é perceber o lúdico e o lazer quando se está dentro da cultura, e outra é instrumentalizá-la para que se reduza a isso. Ainda pode ser interpretado em outro sentido: ao momento em que as obras são expostas apenas como espetáculo, deixando para traz o processo de criação, indica que a cultura é tomada em seu ponto final.

Essa nova relação com a cultura que autora indica na qual considera o processo de criação, significa entendê-la como trabalho da inteligência, da sensibilidade, da imaginação, da reflexão, da experiência e do debate, e como trabalho no interior do tempo, é pensá-la como instituição social, portanto, determinada pelas condições materiais e históricas de sua realização (CHAUI, 2008).

Em relação aos centros de cultura, de acordo com Milanesi (1997), são caracterizados como a união de produtos culturais, a oportunidade de argumentá-los e a oportunidade de elaborar novos produtos. Por isso, pode-se compreender que um centro cultural é um local de ajuntamento de atividades culturais, onde gera criação, reflexão, fruição e compartilhamento de bens culturais.

Apesar de diversos locais serem considerados geradores de cultura, atualmente, os centros culturais são uma junção desses espaços, sendo bibliotecas, galerias, anfiteatros, museus, salas de estudo, oficinas, entre outros espaços que tem como objetivo propagar cultura e informação, além da união social em uma esfera que promove a cultura e lazer (MILANESI, 1997).

Já a expressão casa de cultura pode designar: um centro cultural pequeno, situado em bairros e periferias, com pouco equipamento e acervo com função de reprodução da cultura instituída; modestas instituições direcionadas para a propagação de uma espécie cultural própria, como poesia ou teatro, ou personalidades destacadas (COELHO, 1986).

Milanesi (1997), apresenta a relação entre os centros e a cidade. Segundo o autor, o centro deve comtemplar e responder as necessidades, demanda e desejos da população, propiciando o encontro e junção das pessoas e a cidade, fazendo com que as pessoas compreendam os acontecimentos contemporâneos, prestando serviços aos cidadãos. 
Segundo Coelho (1986), os centros têm o dever de propiciar bases para o surgimento de uma cultura viva, onde se forma pela experiência, implica-se em compreensão, entrega, disciplina e comprometimento. A cultura viva é concebida pelo próprio individuo, em contato com outros indivíduos, com as obras de arte, com as informações; colocados em um processo grupal e dinâmico, crítico, criativo e provocativo.

Independente da condição de atuação dos centros de cultura, os mesmos devem ser espaços inovadores, de descoberta e de revelação da realidade. $O$ autor afirma que um centro deve fazer uma clara opção pelo indivíduo numa situação coletiva; ele só tem razão de existir se está comprometido com a formação de sujeitos e sua inserção na coletividade. Pois, somente a partir da existência de indivíduos é que se pode construir uma coletividade que seja diferente do que se conhece por massa, ou seja, uma coletividade que valorize a diversidade e a individualidade (COELHO, 1986).

Em relação a arquitetura dos centros culturais, ao projetar os ambientes, não é utilizado um molde, onde possui apenas um setor isolado, mas sim, é uma junção de todos eles, de acordo com Milanesi (2003). O padrão a ser seguido para a elaboração da edificação costuma ser tanto focado apenas em uma área de atuação, mas também pode se multiuso e promover variadas ações como as oficinas, leitura em biblioteca, exibição de filmes e teatro, audição musical, entre outros (NEVES, 2012).

A arquitetura dos centros tem o dever de se conectar e manter relação diretamente com o contexto do local onde está inserida. As ligações devem ser primordiais, ocasionando, sobretudo as relações de permeabilidade entre a edificação e a cidade, também é de suma importância o impacto visual que a edificação irá causar na paisagem, muitas vezes alterando a dinâmica, trazendo benéfico até para outras áreas de atuação da cidade.

Ao buscar a origem mais remota dos centros de cultura, Milanesi (1997), direciona-se para um padrão dos complexos culturais presentes na Antiguidade Clássica, sendo a Biblioteca de Alexandria a mais popular. Os centros de cultura atuais representariam uma reaquisição de antigos moldes.

Segundo Silva (1995), a Biblioteca de Alexandria, estabelecia um local com diversas atividades culturais composto por palácios reais que agrupavam inúmeros documentos visando proteger o conhecimento da Grécia Antiga em diversificados campos, como o da ciência, religião, filosofia, entre outros. Deste modo, o lugar atuava como um ambiente de estudos acompanhado de um espaço para a adoração de divindades e abrigava variados objetos. Além disso, possuía um anfiteatro, observatório, salas de trabalho, refeitório, jardim botânico e zoológico. $\mathrm{O}$ modelo descrito é similar com à dos centros de cultura contemporâneos.

Coelho (1997) relata o momento histórico da união de todas as unidades artísticas, de onde se originaram os centros culturais, empregando a concepção de "ação cultural". Denominados de centros de arte, estes ambientes já se encarregavam da realização da ação sociocultural que foi favorecido por políticas culturais socialistas derivadas de alguns países da Europa no século XX. Porém na França, apenas no fim da década de 50 , foram lançados os embasamentos do que atualmente compreendemos como ação cultural. Pelas fontes analisadas pode se perceber que houve um hiato entre a antiguidade e o século XX.

Descrevendo ainda sobre os momentos de ação cultural, Coelho (1997), aborda o segundo momento, que acontece a partir da Segunda Guerra Mundial, abre espaço para uma abordagem social da arte, deslocando o foco da obra de arte para o usuário, compreendido em seu grupo social. A tendência que direcionava a ação-cultural naquele momento é a de fortalecer os laços entre a comunidade. $O$ terceiro momento identificado, tem início no final da década de 60 , quando as ações culturais passam a preocupar-se com o indivíduo e são entendidas como instrumento de criação de projetos individuais.

Em 1975, inaugurado em Paris, o primeiro centro cultural moderno criado na Europa foi o Centre National d'Art et Culture Georges Pompidou (Figura 1). O "Beaubourg", como é nomeado O Centro, por conta de sua localidade na cidade, serviu de molde para a introdução de centros culturais ao redor do mundo. Na França, os centros de cultura se iniciaram como uma alternativa de lazer elaborada para receber os operários franceses (SILVA, 1995). 
Figura 1. Centro Cultural Georges Pompidou

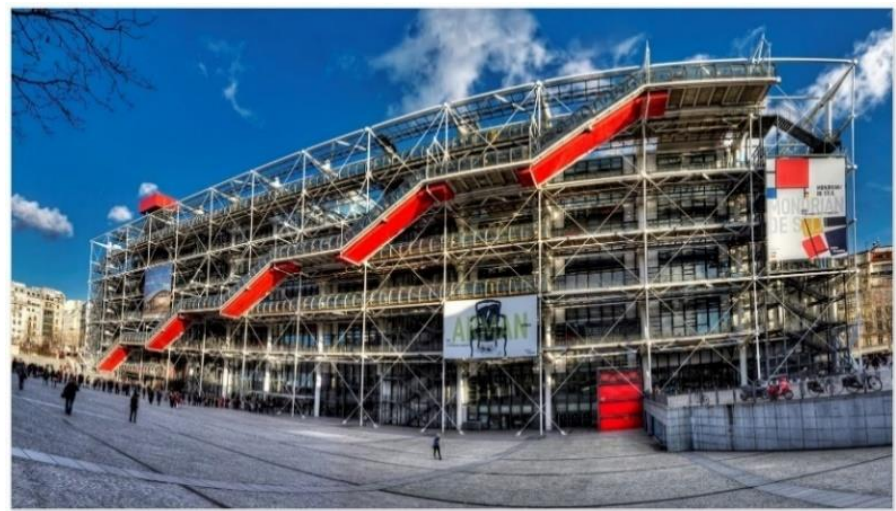

Fonte: 44arquitetura (2018).

De acordo com Meira (2014), a fundação do Centro Cultural Georges Pompidou, despertou o processo da chamada "cultura dos novos museus" como um elemento integrante dos centros culturais, no qual se reproduziu na fundação do museu Guggenheim localizado em Bilbao (Espanha)(Figura 2).

Figura 2. Museu Guggenheim na cidade de Bilbao (Espanha)

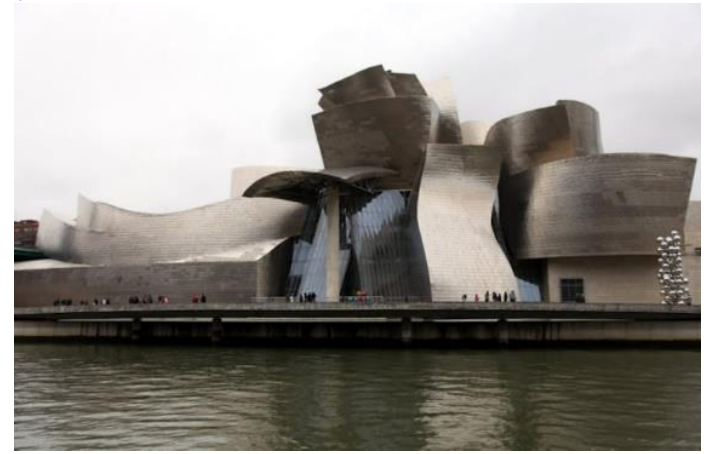

Fonte: Archdaily (2016)

Em seguida no novo Louvre em Abu Dhabi (Emirados Árabes Unidos) (Figura 3), dentre outros.

Figura 3. Novo Louvre em Abu Dhabi (Emirados Árabes Unidos)

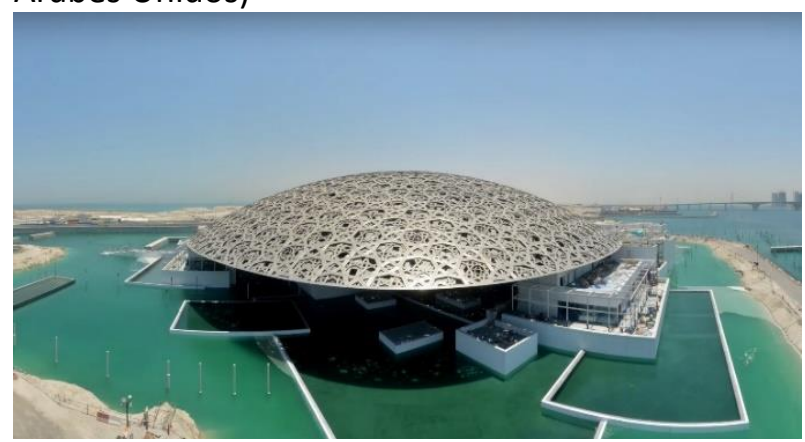

Fonte: 44arquitetura (2017).
Analisando as grandes vantagens, a sociedade mundial foi reconhecendo que os centros de cultura eram inovadores ao se tratar da concepção dos espaços, tornando-se um modelo de evoluído das bibliotecas tradicionais milenares, onde foram ampliadas para diversificadas áreas artísticas, como afirma Ramos (2007). Esse movimento proporcionou e gerou a criação de diversos equipamentos com as mesmas particularidades, sendo adotado por países desenvolvidos e, em seguida, por países subdesenvolvidos, como o Brasil.

A disseminação dos centros de cultura no Brasil ocorreu através dos incentivos ligados ao panorama político do momento, em outros termos, os centros culturais no país tiveram a ajuda do governo. A existência e manutenção desses equipamentos de cultura vinha através dos subsídios fiscais destinamos a esse setor, se tornando perceptível que o crescimento dos mesmos resultava em mais demandas (RAMOS, 2007).

Os primeiros centros de cultura concebidos foram o Centro Cultural São Paulo e o Centro Cultural do Jabaquara, segundo Coelho (1986), a partir destes surge o fenômeno da propagação desses locais espalhados pelo país, sendo caracterizados como os primeiros centros da América Latina.

O centro cultural São Paulo (Figura 4), projetado pelos arquitetos Eurico Prado Lopes e Luiz Telles, está localizado entre a Rua Vergueiro e a Avenida 23 de Maio, o edifício foi um dos que teve maior sucesso e relevância por conta do contexto histórico e da comunidade onde foi implantado. $O$ bairro antes do centro era majoritariamente residencial, depois da inserção do equipamento passou a ser voltado para o cultural (CENTRO CULTURAL SÃO PAULO, 2016). 
Figura 4.Centro Cultural São Paulo

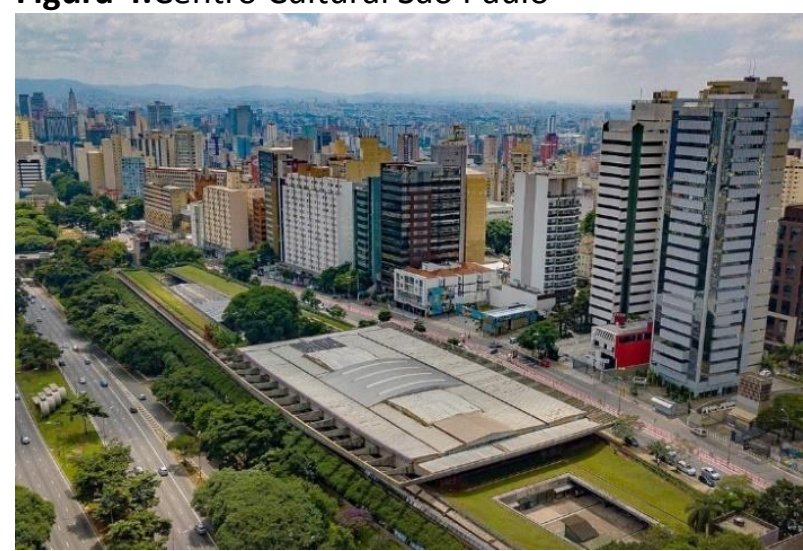

Fonte: Amazingarts (2013).

Outro centro cultural de extrema relevância histórica é o centro cultural Jabaquara (figura 5), projetado em 1977 pelo escritório Shieh Arquitetos Associados, foi fruto de intervenção na Casa-Sede do Sítio Ressaca construída no início do séc. XVIII. Integrado no Projeto CURA/ Jabaquara, a revitalização do monumento histórico constituiu a criação de espaços abertos e fechados para a implantação no local das diferentes atividades culturais (YAU; ROCHA FILHO, 2017).

Figura 5. Centro Cultural Jabaquara

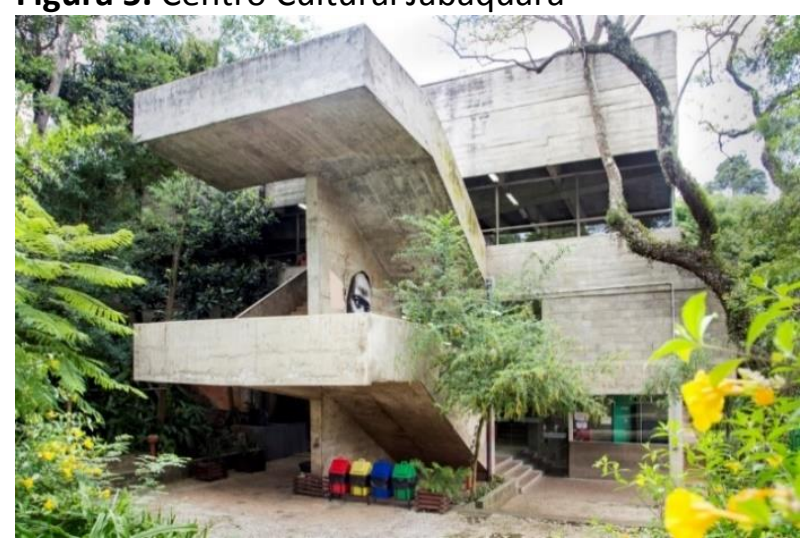

Fonte: Archdaily (2017).
Encerrado o período de introdução dos centros culturais em São Paulo, foram sendo produzidos em variados locais do país quase simultaneamente, como: a "biblioteca pública do estado do Rio de Janeiro (RJ); o espaço cultural José Lins do Rego em João Pessoa (Pe); o CENTUR de Belém do Pará (PA); O Centro de criatividade de Aracajú (SE) e outros" (MILANESI, 2003 apud SANTOS, 2013).

Para Ramos (2007), a partir de então, o incentivo da cultura vem se desenvolvendo nas cidades, onde pode se notar as manifestações culturais custeadas pelo poder privado e poder público, possibilitando construções de notáveis espaços. A indagação a ser analisada é se de fato são eventos de cultura para a comunidade, ou se por trás, é apenas uma imagem para impulsionar cidades e empresas para gerar lucros com a exploração do turismo e comércio cativados por esses locais.

\section{PRESIDENTE PRUDENTE E O CONJUNTO HABITACIONAL JOÃO DOMINGOS NETTO}

Situado no Estado de São Paulo-BR, o município de Presidente Prudente, está a cerca de 558 km, a oeste da Capital, (Figura 6), pertencendo à mesorregião e microrregião do mesmo. Com verões quentes e chuvosos, e invernos frios e secos, sua temperatura média anual geralmente atinge os $21,6^{\circ} \mathrm{C}$, a exposição de Sol pleno sendo uma região de clima tropical chuvoso. Em questão geográfica a região possui variações de altitude, sendo seu nível máximo, de 502 metros (PREFEITURA MUNICIPAL DE PRESIDENTE PRUDENTE, 2019).

Figura 6. Localização do Município de Presidente Prudente

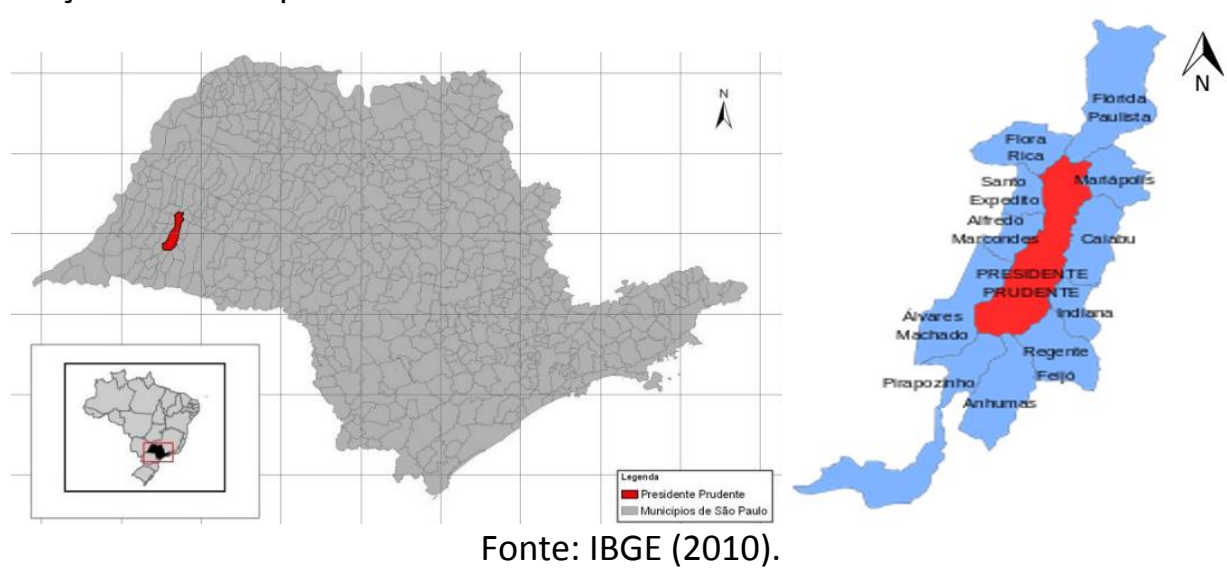


Segundo Whitacker (2017), foi em 1921, que o Município de Presidente Prudente passou a existir de fato, através do desmembramento territorial-administrativo de outras regiões, feito pelos Coronéis Goulart e Marcondes. A partir desde momento, o crescimento do município, gerou diversos acontecimentos, como o surgimento de novas ideias comerciais, novos cultivos como o de algodão, feijão, entre outros.

Com o passar dos anos, o processo de urbanização foi se expandindo através das primeiras avenidas da cidade, a Avenida Washington Luiz, Avenida Manoel Goulart, e Coronel Marcondes, formando o quadrilátero central, sendo o centro da cidade com diversas atividades até os dias de hoje (WHITACKER, 2017).

De acordo com Whitacker (2017), atualmente o crescimento da cidade acontece de maneira diferente em relação ao seu início. Sendo ocupada por condomínios fechados de alto padrão e conjuntos habitacionais voltados para programas sociais em locais mais afastados e periféricos da região central.

Em relação aos conjuntos habitacionais em Presidente Prudente, eles possuem períodos de implantação que variam entre si. Essas diferenças são ligadas ao fato de que as políticas habitacionais na cidade tiveram períodos de atuação diferentes (BARON, 2010).

A Vila Liberdade foi o primeiro conjunto habitacional foi implantado na década de 1960, a partir da instalação de um núcleo habitacional do BNH, com uma composição limitada de 142 residências. $O$ segundo foi $O$ Conjunto Habitacional Bartolomeu Bueno de Miranda que surgiu apenas em 1978, era composto por 1.017 habitações sociais, o que para a época era representativo.

Na década de 1980 foram entregues os conjuntos habitacionais: Parque Alexandrina, Jardim Santa Martha, Jardim Itatiaia, Parque Bandeirantes, Parque Cedral e o Parque Watal Ishibashi. Em 1993, foi implantado o Conjunto Habitacional Ana Jacinta com 2.500 habitações, se tornando representativas na malha urbana da cidade, suscitando a necessidade de criar uma infraestrutura no setor de comércios e serviços.

Houve um hiato de tempo para a implantação dos conjuntos na cidade, apenas em 2013 foi entregue pelo PMCMV o Residencial Tapajós com 227 habitações sociais localizadas na parte norte, junto com ele há a implantação do
Conjunto Habitacional João Domingos Netto que será abortado posteriormente sendo o local de implantação do projeto.

Em relação a cultura, Presidente Prudente possui o Centro Cultural Matarazzo, onde fica locado no edifício das Indústrias Matarazzo que na década de 1937, era uma das grandes referências comerciais da região do Oeste Paulista, com atividades na área da agroindústria, com o descaroçamento e processamento do algodão.

De acordo com a Secretaria da Cultura de Presidente Prudente (20-?), as indústrias atuaram na cidade até a década de 1970, quando houve no país o declínio do complexo industrial. As instalações foram vendidas, arrendadas ou hipotecadas, consequentemente, ficaram abandonadas e desocupadas, surgindo uma luta por parte da comunidade pela recuperação do espaço e sua transformação em Centro Cultural.

Segundo a Secretaria da Cultura de Presidente Prudente (20-?), a recuperação dos velhos galpões iniciou setenta anos depois de suas primeiras atividades. As indústrias Matarazzo ressurgiram, sendo devolvida à cidade novamente com caráter cultural. Nasce um dos mais importantes emblemas da cidade e região do Oeste Paulista, o Centro Cultural Matarazzo (Figura 7), contemplando uma programação difusa de eventos, cursos de formação artística/cultural, atendendo toda a população.

Figura 7. Centro Cultural Matarazzo

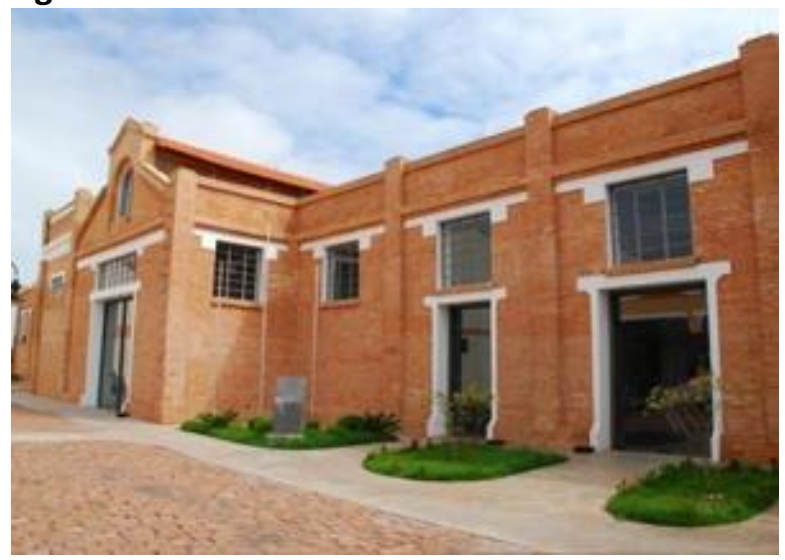

Fonte: Portal Prudentino (2013).

O Conjunto Habitacional João Domingos Netto (CHJDN) localizado na cidade de Presidente Prudente (Figura 8), de acordo com Albano (2019) é o maior empreendimento realizado através do financiamento do Programa Minha Casa Minha Vida (PMCMV) faixa 1. Possui 2.343 unidades 
residenciais, alguns lotes destinados à $950.581,63 \mathrm{~m}^{2}$. implantação de comércios e serviços, lotes institucionais e áreas de lazer, numa área total de

Figura 8. Localização do Conjunto Habitacional João Domingos Netto
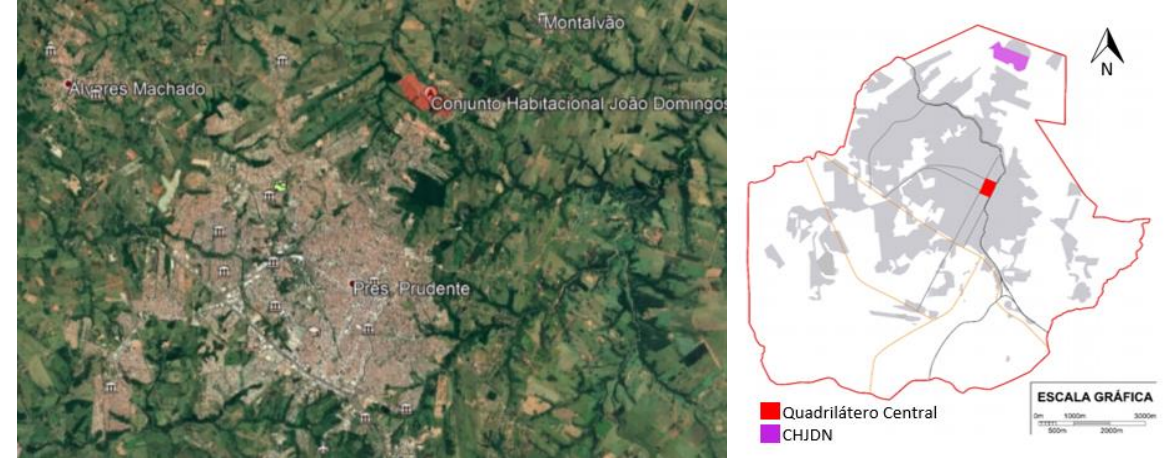

Fonte: Google Earth; Mayara Albano (2019). Modificado pela autora (2021).

Fica localizado na zona norte da cidade, em uma área descontínua à malha urbana, com aproximadamente, $7 \mathrm{Km}$ de distância do centro urbano, próximo à rodovia Raimundo Maiolini, que faz ligação da malha urbana de Presidente Prudente ao distrito de Montalvão, o que inviabiliza os deslocamentos a pé com vistas a realização do consumo de bens e serviços e também para as demais atividades cotidianas dos citadinos (ALBANO, 2019).

De acordo com Albano (2019), o transporte coletivo é o principal meio de locomoção dos moradores, pelo fato do bairro estar distante e descontinuo da malha da cidade, a maioria dos moradores viajam longas distâncias para chegar ao seu local de trabalho, locais de lazer, cultura e compras. A figura 9, apresenta a distância entre 0 conjunto e 0 principal equipamento de cultura da cidade, o Centro Cultural Matarazzo.

Figura 9. Relação do CHJDN e Centro Cultural Matarazzo

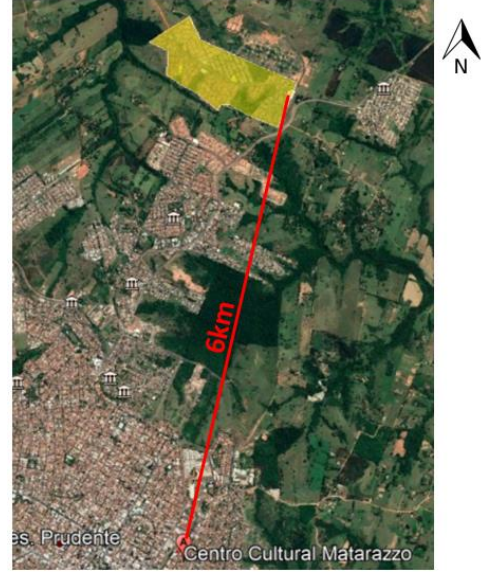

Fonte: Google Earth. Modificado pela autora (2021).
Além disso enfrentam vários problemas com o transporte coletivo, como superlotação nos horários de pico ou a impossibilidade de embarcar no horário desejado devido ao fato de terem poucos veículos cobrindo as linhas que passam pelo conjunto. Outro problema é que as linhas só passam pela avenida principal Maria Menezes de Alcantara Muitos, dificultando o acesso dos usuários que moram longe do local (ALBANO, 2019).

Nos dias atuais o Conjunto possui em funcionamento apenas uma escola de educação infantil, que atende cerca de 150 crianças de até cinco anos de idade. Há uma escola em construção de uma escola estadual com capacidade para atender até 1.500 alunos do ensino fundamental, que precisam se deslocar para outras localidades da cidade (PRESIDENTE PRUDENTE, 2017).

Segundo Albano (2019), há apenas três áreas destinadas ao lazer e esporte possuindo espaços com soluções projetuais de baixa qualidade (Figura 10). Há apenas dois playgrounds infantis em todo conjunto habitacional, apenas uma quadra de areia, poucos espaços cobertos para convivência na maioria delas, não existem bancos suficientes. Ou seja, não há muitas opções para prática de esportes, e atividades recreativas para crianças e jovens. Quanto à localização, os equipamentos existentes, embora tenham em pouca quantidade e poucas opções de atividades eles estão bem distribuídos pelo bairro. 
Figura 10. Áreas de lazer

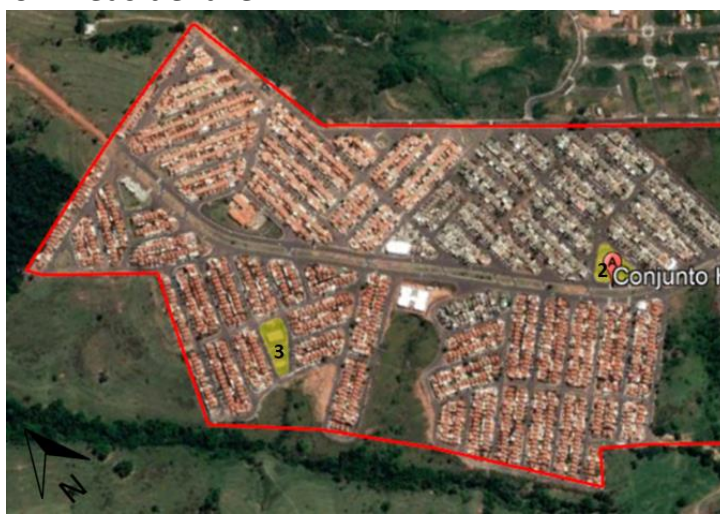

Fonte: Google Earth. Modificado pela autora (2021).

É notório que o Conjunto Habitacional João Domingos Netto, localizado na zona norte, carece de espaços culturais e os equipamentos de lazer que existem, são escassos, subutilizados e precários. Portanto, há ausência de incentivo e de espaços físicos de lazer, cultura e educação no local, sendo um bairro totalmente marginalizado pelo restante da cidade.

Diante do exposto, o presente estudo promoverá além do conhecimento, uma proposta de criação de um polo cultural que fomente o pertencimento com os usuários, a interação entre os moradores e estimule uma identidade ao local.

\section{DIRETRIZES PROJETUAIS}

O terreno escolhido para o projeto do Centro de Cultura e Lazer, foi um lote institucional no Conjunto Habitacional João domingos Netto (Figura 11). Se situa no início do bairro, próximo a rotatória de acesso sua face frontal é voltada para Avenida principal Maria Menezes Alcântara, sua localização privilegiada trará maior visibilidade e fácil acesso ao Centro de Cultura e Lazer.

Figura 11. Localização do terreno

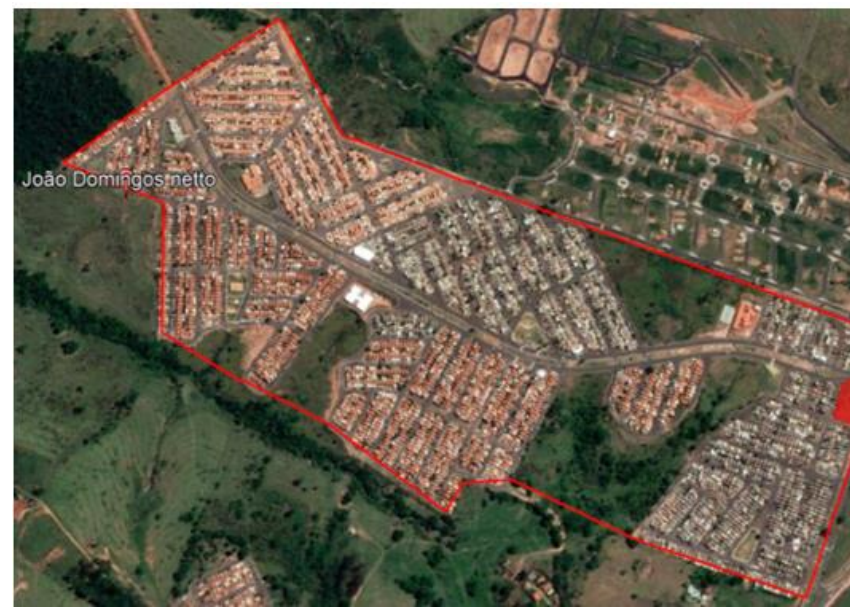

Fonte: Google Earth. Modificado pela Autora (2021)
O projeto tem como conceito buscar a valorização da simplicidade, estimular a relação de pertencimento e conexão entre os moradores do conjunto e o edifício (Figura 12), oferecendo a comunidade um local acolhedor de cultura, lazer e aprendizagem, trazendo interação com a paisagem e ao contexto local.

Figura 12. Conceito projetual SIMPLICIDADE

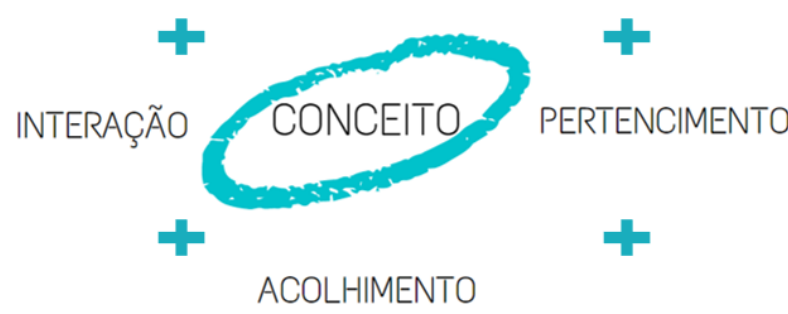

Fonte: Asautoras (2021)

Partindo-se de quadro blocos longilíneos retangulares que exploram a horizontalidade do local, destinados aos setores de cultura/educação, serviços e lazer, utilizando-se da tipologia pátio são ligados por um vazio livre central onde se torna o principal responsável pelo fluxo e passagem do local. Como pode ser observado abaixo na figura 13.

Figura 13. Tipologia pátio

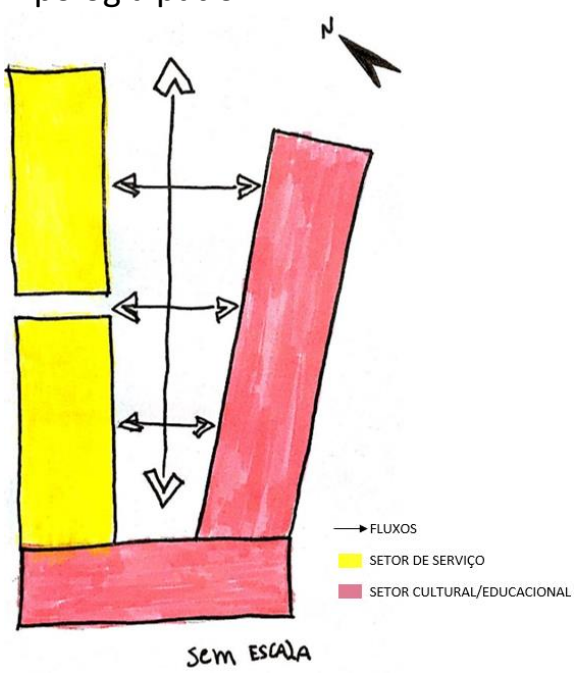

Fonte: A autoras (2021).

Esse pátio central também servirá como ambiente multiuso e de convivência, se tornando um espaço democrático, onde possibilitará diversas atividades como exposição de artesanatos confeccionados no Centro, cinema comunitário, lazer, ou até mesmo como teatro em dias de chuva, já que o anfiteatro existente será descoberto. 
Também fazendo o aproveitamento da topografia natural, o local contará com um anfiteatro a céu aberto onde possuirá uma espécie de arquibancada que serão utilizadas pelo público como assentos, que vencerá os desníveis existentes (figura 14).

Figura 14. Croqui do Anfiteatro

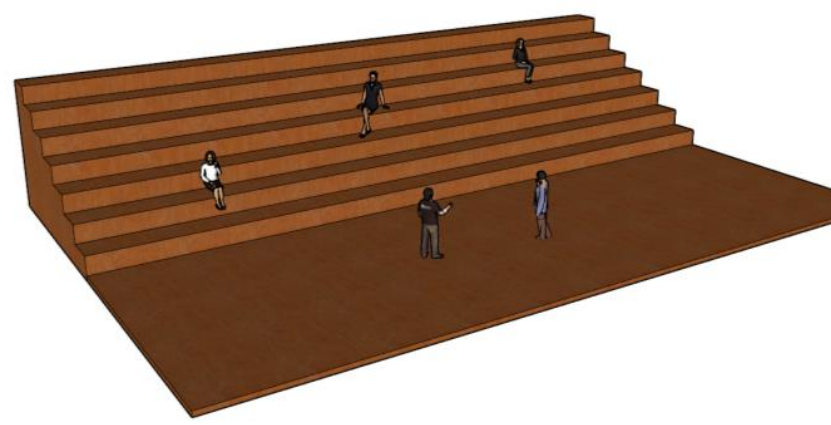

Fonte: As autoras (2021).

Com essa mesma ideia, será implantada também uma horta onde os usuários poderão aprender sobre plantio e também será utilizada para os cursos de culinária e para o café do próprio Centro (figura 15).
Figura 15. Croqui da horta

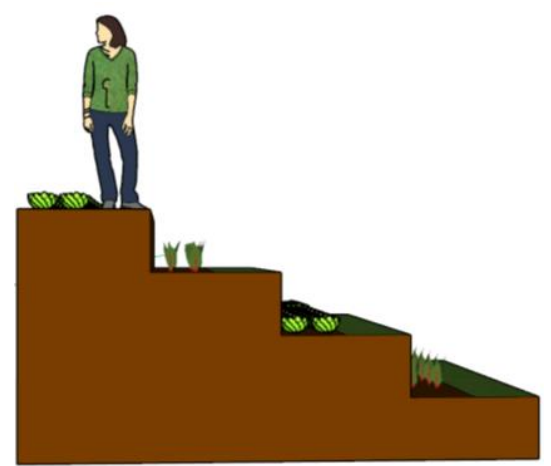

Fonte: As autoras (2021).

No croqui de implantação (Figura 16) é possível entender a forma como o edifício foi inserido no terreno, além da identificação dos acessos e ambientes externos como a praça, os escorregadores, horta, anfiteatro e o estacionamento.

Figura 16. Implantação e acessos

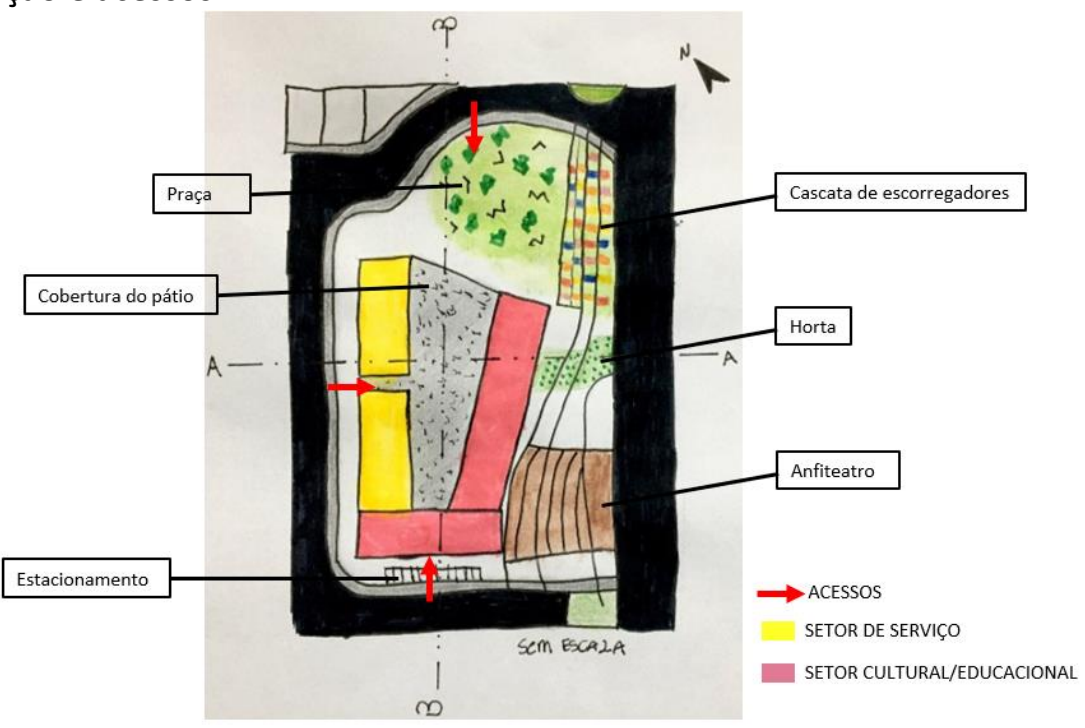

Fonte: As autoras (2021).

O corte esquemático transversal abaixo (figura 17), apresenta a utilização da topografia para a implantação dos blocos e ambientes, buscando uma relação entre eles, onde observase que o edificado se localiza na parte mais alta. Também é identificado os acessos ao local, que se dão através do bloco de serviços, estacionamento e praça. 
Figura 17. Corte $A A$

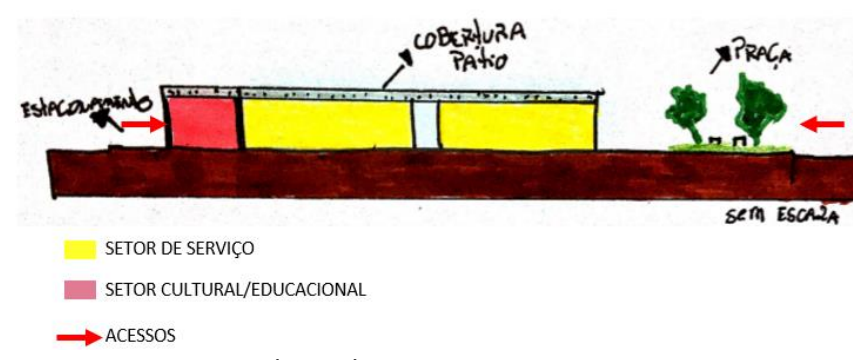

Fonte: As autoras (2021).

Ao definir o programa de necessidades, setores e a implantação de cada bloco, concluiuse que o projeto possuirá 4 blocos com volumes simples e retangulares, mediante ao conceito de tipologia pátio, os volumes formam um vazio interno coberto e se localizam na parte mais elevada do terreno, um dos blocos também se abrem para área externa, o pátio também dá acesso a praça e a cascata de escorregadores, esses fatores podem ser observados abaixo na figura 18.
Figura 20. Volumetria do projeto

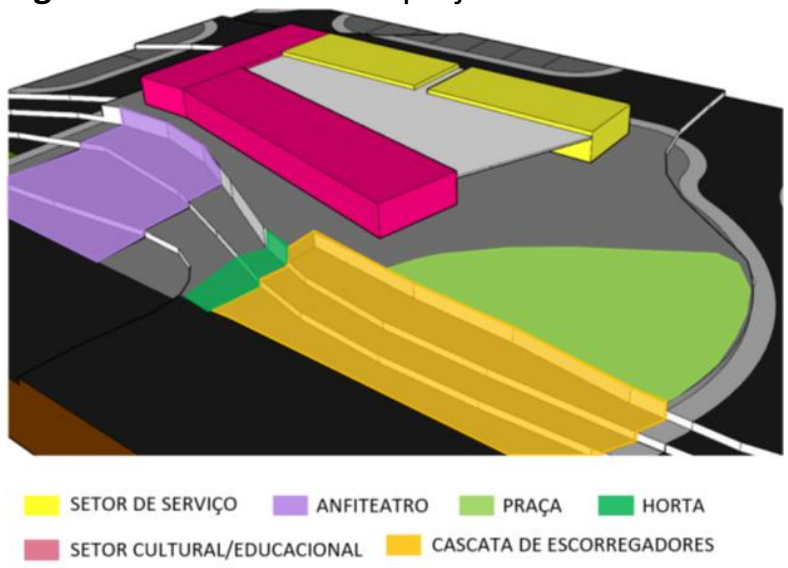

Fonte: As autoras (2021).

A figura 21 traz a análise da insolação no terreno, o projeto foi pensado para que se tenha o melhor aproveitamento possível da mesma, os ambientes externos como o anfiteatro, a cascata de escorregadores, horta e praça ficam localizados a leste do terreno, tendo menor incidência do sol pela manhã, a fim de não causar incomodo aos usuários.

Figura 21. Estudo de insolação

Fonte: As autoras (2021).

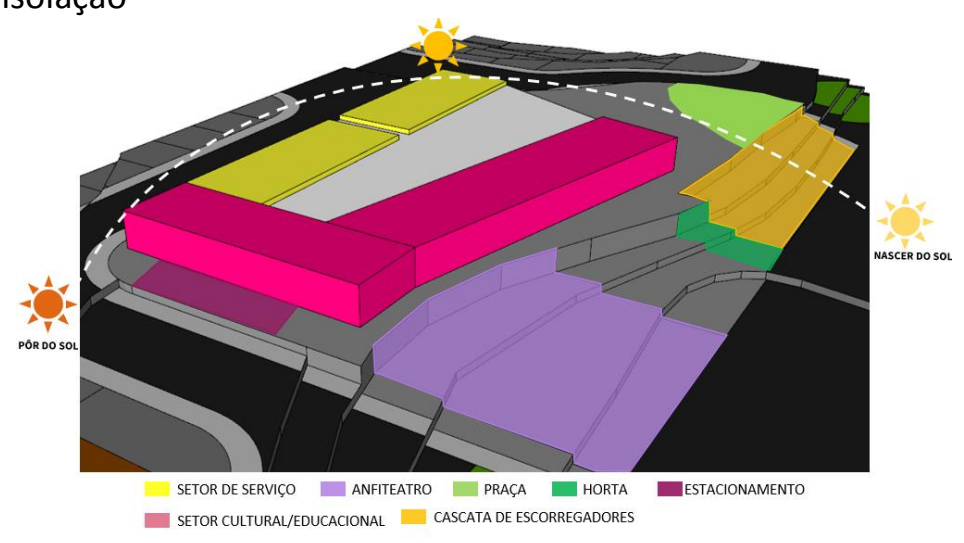

O local de maior insolação ocorre em uma das fases do edifício, onde, também está localizado o estacionamento, como tentativa de minimizar o problema, serão aplicadas vegetações e brises coloridos como os da escola em Alto Pinheiros localizada em São Paulo, de autoria dos escritórios Base Urbana e Pessoa Arquitetos (figura 22) (DELAQUA, 2016). 
Figura 22. Brises coloridos

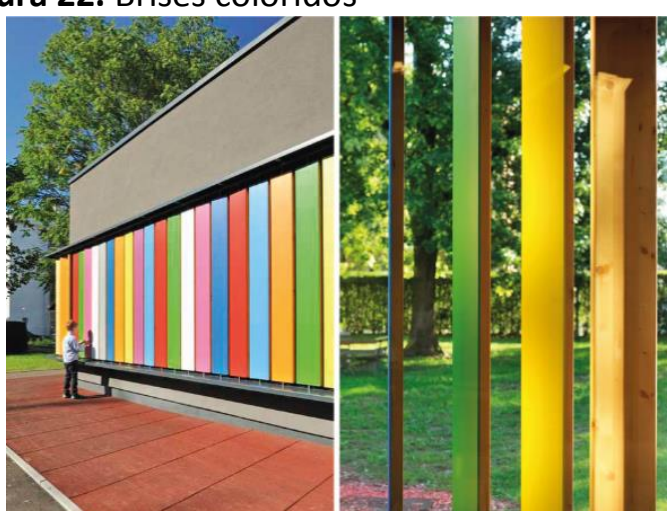

Fonte: Galeria da Arquitetura (2016).

\section{CONSIDERAÇÕES FINAIS}

Através das pesquisas e levantamentos trazidos nesse conclui-se que o projeto terá como objetivo oferecer espaços de qualidade de cultura e lazer ao Conjunto João Domingos Netto, já que foi constatado a carência desses tais equipamentos no local, reconhecendo a importância que esses fatores têm em relação ao desenvolvimento e aprendizagem do indivíduo como um todo. $O$ projeto irá criar uma identidade para o local, desenvolvendo a relação de pertencimento dos moradores para com o mesmo.

Para que o Centro seja atrativo, com ambientes estimulantes e que proporcionem bem-estar aos usuários, foram traçados através dos levantamentos, diretrizes projetuais que irão viabilizar a realização do projeto.

\section{REFERÊNCIAS}

ALBANO, M. Qualidade ambiental na produção de habitação de interesse social em Presidente Prudente/SP: o caso dos conjuntos Ana Jacinta e João Domingos Neto. 2019. Tese (Doutorado em Geografia) - Universidade Estadual PaulistaUnesp, Presidente Prudente, 2019. Disponível em:

https://repositorio.unesp.br/handle/11449/1915 59. Acesso em: 28 mar. 2021.

BARON, C. M. P. A Produção da Habitação e os Conjuntos Habitacionais dos Institutos de Aposentadorias e Pensões - IAPs. Revista Tópos, v. 5, p. 102 - 126, 2010.

Disponível em: https://revista.fct.unesp.br/index.php/topos/arti cle/view/2287. Acesso em: 2 maio 2021.

CARDOSO, C. B.; MILANI, M. L. Políticas Públicas de Cultura, Esporte e Lazer: o Local expressa o
Regional sob a versão da juventude de São Mateus do Sul-Paraná. Universidade do Contestado, 2015. Disponível em:

https://www2.faccat.br/portal/sites/default/files Lcardoso milani.pdf. Acesso em: 17 abr. 2021.

CENTRO CULTURAL SÃO PAULO. História. São Paulo, 2016. Disponível em: http://centrocultural.sp.gov.br/site/institucional/ historia/. Acesso em: 13 mar. 2021.

CHAUI, M. Cultura e democracia. Crítica y Emancipación, v. 1, p. 53-76, junio, 2008.

COELHO, T. $\mathbf{O}$ que é indústria cultural. São Paulo: Brasiliense, 1986. Disponível em: https://docplayer.com.br/22777-O-que-eindustria-cultural-teixeira-coelho.html. Acesso em: 11 mar. 2021.

DELAQUA, V. Escola em Alto de Pinheiros/Base Urbana + Pessoa Arquitetos. ArchDaily Brasil, $2016 . \quad$ Disponível em: <https://www.archdaily.com.br/br/797184/escol a-em-alto-de-pinheiros-base-urbana-plus-pessoaarquitetos >. Acesso em: 11 de maio de 2021.

MEIRA, M. R. M.. A cultura dos novos museus: Arquitetura e estética na contemporaneidade. 2004. Tese (Doutorado) - Universidade de São Paulo, Faculdade de Filosofia, São Paulo, 2014. Disponível em: https://teses.usp.br/teses/disponiveis/8/8133/td e-27062014-105015/pt-br.php. Acesso em: 20 mar. 2021.

MILANESI, L. A casa da invenção. São Caetano do Sul: Ateliê Editorial, 1997. Disponível em: https://www.researchgate.net/publication/3076 82421_Bibliotecas_ou_centros_de_cultura. Acesso em: 9 mar. 2021.

NEVES, R. R. Centro Cultural: a cultura à promoção da arquitetura. Especialize - Instituto de Pós-Graduação, Goiânia, 2012. Disponível em: <https://doczz.com.br/doc/191671/centro cultural--a-cultura-\%C3\%AOpromo\%C3\%A7\%C3\%A3o-da-arquitetura>. Acesso em: 9 de março de 2021. 
PRESIDENTE PRUDENTE. Prefeito anuncia construção de creche no João Domingos Netto. Presidente Prudente, 2017. Disponível em: http://presidenteprudente.sp.gov.br/site/noticias .xhtml?cod=35144. Acesso em: 24 abr. 2021.

RAMOS, L. B. Centro Cultural: Território privilegiado na ação cultural e informacional na sociedade contemporânea. In: ENECULT ENCONTRO DE ESTUDOS MULTIDISCIPLINARES EM CULTURA, 3., 2007,. Anais [...]. Salvador: Faculdade de Comunicação/UFBa 2007a.

SANTOS, J.L. O que é cultura. São Paulo. Ed. Brasiliense, 1996.

SECRETARIA DA CULTURA DE PRESIDENTE PRUDENTE. Centro Cultural Matarazzo s/a irf Matarazzo. 20-?. Disponível em: http://www.culturapp.com.br/equipamento/cent ro-cultural-matarazzo/. Acesso em: 29 abr. 2021.

SILVA, M. C. S. Centro cultural - construção e reconstrução de conceitos. 1995. Dissertação (Mestrado em Memória Social e Documento) Centro de Ciências Humanas - UNI-RIO. Rio de Janeiro, 1995.

WHITACKER, A. Atlas Ambiental escolar de Presidente Prudente. Espaço Urbano. Origem do núcleo urbano e expansão territorial de Presidente Prudente. Presidente Prudente: Universidade Estadual Paulista - UNESP, 2017. Disponível em:

http://portaldoprofessor.fct.unesp.br:9000/topic o/formacao/socioespacial/. Acesso em: 29 mar. 2021.

YAU, S. S.; ROCHA FILHO, G.N. Clássicos da Arquitetura: Centro Cultural Jabaquara. Shieh Arquitetos Associados. Archdaily, 2017. Disponível em: https://www.archdaily.com.br/br/870322/classic os-da-arquitetura-centro-cultural-jabaquarashieh-arquitetos-associados. Acesso em: 16 mar. 2021. 